\title{
Minimum prevalence, birth incidence and cause of death for Prader-Willi syndrome in Flanders
}

\author{
Annick Vogels ${ }^{1}$, Jenneke Van Den Ende ${ }^{2}$, Kathelijne Keymolen ${ }^{3}$, Geert Mortier ${ }^{4}$, \\ Koen Devriendt $^{1}$, E Legius ${ }^{1}$, and JP Fryns*,1 \\ ${ }^{1}$ Centre for Human Genetics, University of Leuven, Leuven, Belgium; ${ }^{2}$ Centre for Medical Genetics, University Hospital, \\ University of Antwerp, Antwerp, Belgium; ${ }^{3}$ Centre for Medical Genetics, Dutch-speaking Brussels Free University \\ (Vrije Universiteit Brussel), Belgium; ${ }^{4}$ Center for Medical Genetics, Ghent University Hospital, Belgium
}

The identification of all people with a diagnosis of Prader-Willi syndrome (PWS) confirmed by DNA methylation analysis living in Flanders was attempted through contact with the four genetic centres and the PWS Association. The birth incidence for the period 1993-2001 was 1:26 676, the minimum prevalence at 31 December 2001 was 1:76574. A decreasing number of cases with age was found, which can be explained by a number of missing cases in the older population, a higher neonatal mortality in the past and an increasing mortality with age. Childhood death is usually sudden and associated with respiratory infection and high temperature, while the cause of death in adults is considered to be circulatory or respiratory in origin.

European Journal of Human Genetics (2004) 12, 238-240. doi:10.1038/sj.ejhg.5201135

Published online 17 December 2003

Keywords: Prader-Willi; prevalence; birth incidence

\section{Introduction}

The Prader-Willi syndrome (PWS) is a complex disorder characterised by neonatal hypotonia and feeding problems, childhood-onset hyperphagia and obesity, short stature, facial dysmorphism, hypogonadism, learning difficulties and behavioural difficulties. ${ }^{1}$

PWS is caused by abnormalities of the 15q11-13 region including paternal interstitial deletion, ${ }^{2}$ maternal uniparental disomy, ${ }^{3,4}$ deletion of the imprinting centre ${ }^{5}$ or other abnormalities in the imprinting process. ${ }^{5,6}$ Since 1992, clinical diagnosis can be confirmed molecularly by DNA methylation tests. ${ }^{7}$ With the combined use of FISH, cytogenetic and molecular techniques, the precise genetic defect (deletion, translocation, uniparental disomy, imprinting centre deletion or imprinting mutation ) can now be identified in all patients.

*Correspondence: Professor JP Fryns, Centre for Human Genetics, Herestraat 49, B-3000 Leuven, Belgium. Tel: + 3216 345899;

Fax: + 3216346051 ;

E-mail: Jean-Pierre.Fryns@med.kuleuven.ac.be

Received 21 May 2003; revised 27 August 2003; accepted 30 October 2003
Data on prevalence and birth incidence vary from 1 in 5000 to 1 in $30000 .^{8}$ Most authors estimate the prevalence based on clinical diagnoses within a small population (less than 265000 ) and a limited age group (under 30 years).$^{8-10}$ A recent study including all ages, ${ }^{11}$ found a birth incidence of 1:29000, a prevalence of 1:52 000 and a mortality rate of $3 \%$ a year across all ages and 7\% a year in those over 30 years of age. Common causes of death in PWS adults are obesity related cor pulmonale and respiratory failure, ${ }^{12}$ while unexpected sudden death in childhood is associated with acute respiratory failure and/or high fever. ${ }^{13}$

Here, we report the findings of a prevalence study including all ages in Flanders, a well-defined geographic region with a population of approximately 6 million people. Data on prevalence, birth incidence and causes of death are given.

\section{Materials and methods}

The method of counting down all known cases with a diagnosis confirmed by DNA methylation testing using probes PW71B and KB17 was used. Patients were ascer- 
tained through the four genetic centres of Flanders and the Flemish PWS Association. Data on causes of death and age at diagnosis were obtained from the medical files.

The number of births from 1993 to the end of 2001 was obtained from the annual reports of the Study Centre for Perinatal Epidemiology (Studiecentrum voor Perinatale Epidemiologie-SPE), which registers over $99 \%$ of all live and stillborn children with a birth weight of more than $500 \mathrm{~g}$.

Differences in median age at diagnosis were tested using a nonparametric test (Mann-Whitney $U$-test) because the data did not show a normal distribution. Differences in prevalences were tested with a $\chi^{2}$ test. All statistical tests were performed with the SYSTAT 7 for windows program (SP55 Inc., Chicago, USA).

\section{Results}

The annual birth rate in Flanders ranges from 66780 in 1993 to 62128 in 2000 with a total of 506851 births. A total of 19 children diagnosed with PWS were born during this 8-year period. The estimated annual incidence of PWS in the period $1993-2000$ is therefore $1 / 26676$ (95\% CI $1 /$ 16 393-/50 000).

On 31 December 2001, 78 persons, 39 males and 39 females, were identified. The age range was from 0 to 56 years with a mean age of 26 years. The population of Flanders was 5972781 giving a prevalence of 1:76574. Flanders is subdivided into five regions and region prevalences vary from 1:49911 up to 1:91802.

Fifty-four patients had a deletion (69\%), 15 patients had a uniparental maternal disomy (19\%) and four patients had an imprinting mutation (5\%). The underlying genetic defect was not identified in the five other patients $(6 \%)$. Figure 1 shows the frequencies by age grouped in 5 year intervals. Ages were standardised to midnight on 31 December 2001. The overall age structure of this sample shows that there is a decreasing number of PWS individuals with age. This decline in prevalence could be explained by a low rate of identification of older PWS individuals and/or by a high rate of mortality in the older age group.

A low rate of identification is supported by age at diagnosis data collected for a group of 64 persons out of the total 78 persons (Figure 2). No exact data were available on the other 14 persons. The median age at diagnosis for the group born after 1981 (aged 20 years or younger) is 26 weeks with a range from 1 week to 8 years, while the median age at diagnosis for the group born before 1981 (older than 20 years) is 10 years with a range from 1 week to 52 years. The difference is statistically significant (Mann-Whitney $U$-test; $P<0.001$ ).

Causes of death are reported in Table 1.

\section{Discussion}

The estimated annual birth incidence of PWS (1/26676) found in this study is in remarkable good agreement with

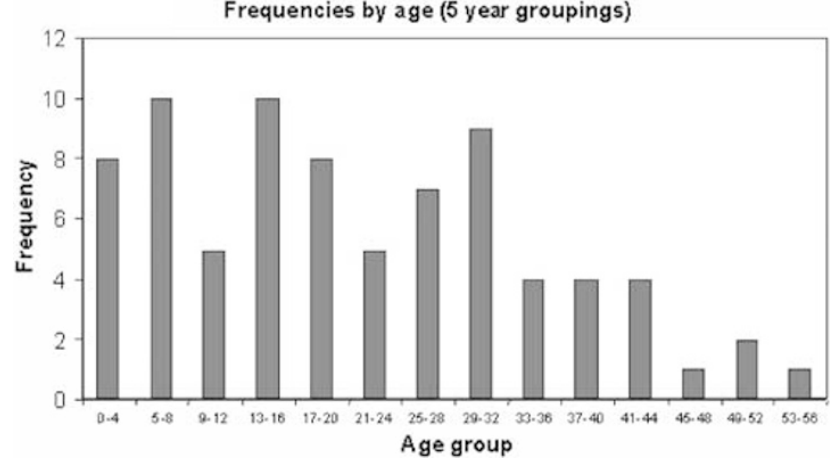

Figure 1 Frequencies by age (5 year groupings). Ages were standardised to midnight on 31 December 2001.

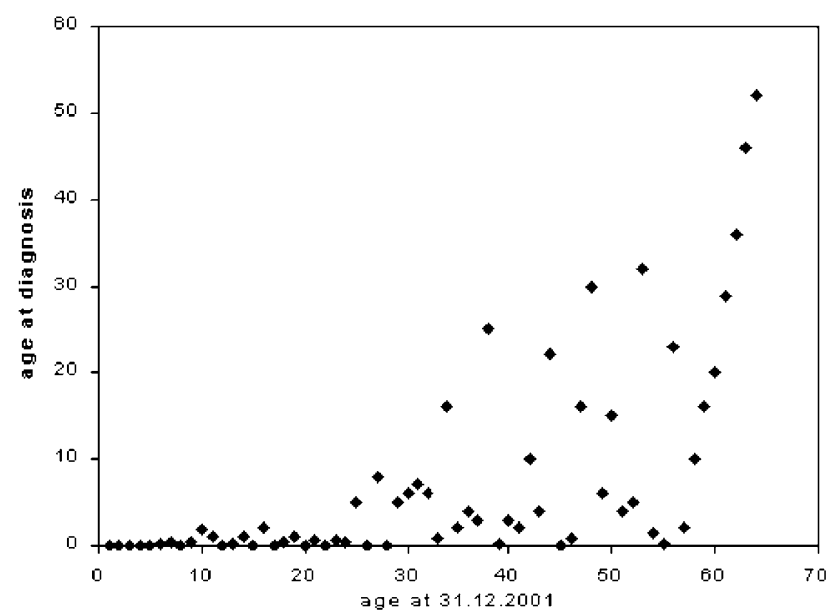

Figure 2 Age at diagnosis $(n=64)$. Ages were standardised to midnight on 31 December 2001.

the lower estimate for birth incidence of 1:29000 found in the study of Whittington et $a^{11}$ and a minimum estimate of 1:25000 in Australia. ${ }^{14}$

The estimated minimum prevalence (1:76574) is significantly lower than the prevalence found by Whittington et $a{ }^{11}{ }^{11}(1: 52000)\left(\chi^{2}=6.47, P=0.01\right)$. The difference can be partly explained by ascertainment differences. In the UK study, 28 out of 96 PWS patients were diagnosed on a clinical base without confirmation by DNA methylation analysis. Leaving out these 28 patients, the prevalence would be $1: 73529$, a rate similar to ours.

A potential source of error in our results is the missing cases. Evidence for missing cases is the regional variation in prevalence, possibly indicating a better identification in some areas than in others. However, such variation may also indicate random variation in smaller groups. Further evidence for the missing cases hypothesis is the decreasing number of cases with age. Data from the older age group may be still missing. The overall structure of current age versus age at diagnosis suggests that some older persons 
Table 1 Mortality in PWS

\begin{tabular}{|c|c|c|c|c|c|}
\hline$I D$ & Sex & Mutation & $B M I\left(k g / m^{2}\right)$ & $\begin{array}{l}\text { Age at death } \\
\text { (years) }\end{array}$ & Cause of death \\
\hline 1 & $\mathrm{~F}$ & del & 16.88 & $10 / 12$ & Pneumonia with high temperature \\
\hline 3 & $\mathrm{~F}$ & del & NK & 9 & Acute-onset pneumonia \\
\hline 4 & M & del & 56.25 & 32 & $\begin{array}{l}\text { Postoperative chronic abdominal abscess and fistulisation } \\
\text { (complicated surgery for abdominal hernia). Three years later: } \\
\text { sudden respiratory infection with high temperature } \\
\text { necessitating intubation and complicated by urinary tract } \\
\text { infection, sepsis, vasculitis, hypotension and status epilepticus }\end{array}$ \\
\hline 5 & M & del & 36.93 & 33 & Car accident \\
\hline 6 & $\mathrm{~F}$ & del & NK & 45 & Second cerebrovascular stroke \\
\hline 7 & M & del & 41.93 & 50 & Cardiorespiratory failure following pneumonia and myelitis \\
\hline
\end{tabular}

Nondel: nondeletion including uniparental maternal disomy or imprinting mutation; Del: deletion; NK: not known.

with PWS, born before the syndrome was well known and in whom the diagnosis was never considered, may not yet have been diagnosed or may have been diagnosed only clinically without genetic confirmation. Increasing availability of genetic tests like identification of the deletion (1981) and DNA methylation tests (1992) has resulted in increasing number of diagnoses. Patients born later than 1981 are diagnosed at a younger age than persons born before 1981 .

The low prevalence rate in the older age group may also be explained by a higher neonatal mortality before 1980. In the past 40 years, an increasing knowledge in medical neonatal care has reduced the neonatal mortality for the total population of Belgium from 10\% in 1930 to $3 \%$ in $1960^{15}, 1 \%$ in $1980^{16}$ and $0.5 \%$ in 2001 (Institute for Perinatal Epidemiology). A third explanation for the falling number of cases with age may be the increasing rate of mortality. Although numbers are small, our data confirm an increased rate of mortality after the age of 30 years. Infections and complications of obesity affecting cardiovascular and respiratory systems are the main risk factors associated with mortality in adults. Sudden respiratory infections with high temperature not responding to treatment with antibiotics and antipyretics medication seem to be the major cause of death in young children.

\section{Acknowledgements}

We thank Professor Dr G Matthys for the molecular analysis and the Flemish PWS association for their help with this study.

\section{References}

1 Cassidy SB: Prader-Willi syndrome. J Med Genet 1997; 34: 917-923.

2 Ledbetter DH, Riccardi VM, Airhart SD, Strobel RJ, Keenan BS, Crawford JD: Deletions of chromosome 15 as a cause of the Prader-Willi syndrome. N Engl J Med 1981; 304: 325-329.
3 Nicholls RD, Knoll JH, Butler MG, Karam S, Lalande M: Genetic imprinting suggested by maternal heterodisomy in nondeletion Prader-Willi syndrome. Nature 1989; 342: 281-285.

4 Robinson WP, Bottani A, Xie YG et al: Molecular, cytogenetic, and clinical investigations of Prader-Willi syndrome patients. Am J Hum Genet 1991; 49: 1219-1234.

5 Buiting K, Saitoh S, Gross S et al: Inherited microdeletions in the Angelman and Prader-Willi syndromes define an imprinting centre on human chromosome 15. Nat Genet 1995; 9: 395-400.

6 Nicholls RD, Saitoh S, Horsthemke B: Imprinting in Prader-Willi and Angelman syndromes. Trends Genet 1998; 14: 194-200.

7 Dittrich B, Robinson WP, Knoblauch $\mathrm{H}$ et al: Molecular diagnosis of the Prader-Willi and Angelman syndromes by detection of parent-of-origin specific DNA methylation in 15q11-13. Hum Genet 1992; 90: 313-315.

8 Burd L, Vesely B, Martsolf J, Kerbeshian J: Prevalence study of Prader-Willi syndrome in North Dakota. Am J Med Genet 1990; 37: 97-99.

9 Akefeldt A, Gillberg C, Larsson C: Prader-Willi syndrome in a Swedish rural county: epidemiological aspects. Dev Med Child Neurol 1991; 33: 715-721.

10 Ehara H, Ohno K, Takeshita K: Frequency of the Prader-Willi syndrome in the San-in district, Japan. Brain Dev 1995; 17: $324-326$.

11 Whittington JE, Holland AJ, Webb T, Butler J, Clarke D, Boer H: Population prevalence and estimated birth incidence and mortality rate for people with Prader-Willi syndrome in one UK Health Region. J Med Genet 2001; 38: 792-798.

12 Stevenson DAATM, Clayton-Smith J, Hall BD et al: Unexpected death and critical illness in Prader-Willi syndrome: report of ten individuals. Am J Med Genet Part A 2003, Early view: June 16 (in press, online available at www3.interscience.wiley.com/cgi-bin/ jissue/77002064).

13 Schrander-Stumpel CTRM, Curfs LMG, Sastrowijoto P, Cassidy SB, Schrander JJP, Fryns JP: Prader-Willi syndrome: causes of death in an international series of 27 cases. Am J Med Genet Part A 2003, Early view: June 16 (in press, online available at www3.interscience.wiley.com/cgi-bin/jissue/77002064).

14 Smith A, Egan J, Ridley G et al: Birth prevalence of Prader-Willi syndrome in Australia. Arch Dis Child 2003; 88: 263-264.

15 Poulain M, Tabutin D: Mortality at a young age in Belgium from 1840 to 1970]. Popul Famille 1977; 42: 49-86.

16 Dujardin B, Vandenbussche P, Buekens P, Wollast E: Evoluton récente de la mortalité infantile. Le cas de Belgique [Recent trends in infant mortality. The case of Belgium]. Arch Fr Pediatr 1986; 43: $275-278$. 